\title{
Operational Reliability of the Rotary Cup Burner Type Saacke - SKV 60 of Marine Boiler
}

\section{Joško Dvornik, Srđan Dvornik}

One of the steps in predicting the reliability of a system includes determining the failure rate of the system's components. The latter is obtained on the basis of the data available to the manufacturer, experience in using similar systems, using statistical methods and technical literature. In practice, the starting point in the process of foreseeing the reliability of any technical system is the assumption of constant failure rates. The system components' failure rates which are determined in this way represent the so-called nominal values. This value is commonly modified by taking into account operation loads and environment conditions under which the observed system component is supposed to operate. In most cases the quantitative values of these two factors result from the engineering assessment that is based on the data available to the manufacturer or the user and takes into account the inevitable effect of a number of subjective factors. Predicting reliability is a process of determining numerical values which show the probability that machinery or engine will meet previously set requirements. The basic objective of reliability prediction is to ensure timely maintenance. This paper discusses predicting the operational reliability of the rotary cup burner type SAACKE - SKV 60 in the marine steam boiler TPK/VIC 8.5/7.

\author{
KEY WORDS \\ $\sim$ Marine boiler \\ $\sim$ Rotary cup burner \\ $\sim$ Reliability \\ $\sim$ Failure
}

\section{INTRODUCTION}

There are four sources of data for predicting the reliability of a system in the stage of development:

- manufacturer;

- $\quad$ experience in using similar systems;

- adequate statistical methods;

- technical literature.

The system as a whole is the starting point when gathering the information necessary for reliability forecasting. If the data referring to a system are not available, it is necessary to decompose the system to the levels for which the data are available. It is neither necessary nor recommended to go any further, even in the event of stopping at the first level below the system level.

However, it is sometimes necessary to reach the most elementary components of the system as it is at this level that the data required can be gathered.

When predicting the operational reliability of a marine steam boiler rotary cup burner (Vujanović, 1987), it is necessary to:

- define the rotary cup burner as a system;

- define faults;

- define operational and maintenance conditions;

- $\quad$ set the algorithms for calculating the reliability;

- determine the failure rates for separate components of the rotary cup burner;

- modify the fault indexes for the burner components;

- calculate the reliability of the rotary cup burner.

When defining the rotary cup burner as a system, it is necessary to determine its components and their relationships. 
The components represent the subsystems of the rotary cup burner. A fault is defined as an occurrence of conditions that impede the rotary cup burner's operation. The operational conditions determine the rotary cup burner's working conditions. The maintenance conditions affecting the reliability of the rotary cup burner must be known before reliability prediction. The block diagram of reliability presents the functional connection of the system or the blocks within the system. The rotary cup burner's reliability is obtained by introducing the values of the failure rates of the system components into the algorithm for calculating the reliability in a defined period of time.

\section{CONSIDERING THE ASSUMPTION ABOUT THE CONSTANT FAILURE RATE}

The above mentioned procedure for predicting the reliability does not assume that the failure rate has to be constant. It is known that the failure rate for most electronic components is constant, i.e. not dependent on time. Although the failure rates for other components depend on time, it has been found out that these changes are small considering the long period of operation of these components.

In both cases a minor error is made by introducing the assumption about the constant failure rate. If the failure rates of components are independent of time, then the reliability of a system comprising such components could be calculated by applying the exponential distribution (Vujanović, 1987), therefore:

$$
R_{g}=e^{-\lambda_{g} t}
$$

where $R_{g}$ is the reliability of the system - the rotary cup burner, and $\lambda_{g}$ is the failure rate of the system.

In the case of sequence configuration $\lambda_{g}$ is calculated from the equation:

$$
\lambda_{g}=\sum_{i=1}^{n} \lambda_{i}
$$

where $\lambda_{i}$ is the failure rate of the $i$ component of the system the rotary cup burner.

It should be noticed that in this case the mean time between failure of the system - the rotary cup burner $M_{g}$ can be calculated from:

$$
M_{g}=\frac{1}{\lambda_{g}}[h]
$$

Even in the event of major changes in failure rates dependent on time, minor mistakes result from using the socalled stable failure rate in foreseeing the reliability of a system over a certain period of time provided that the period of time corresponds to the period for which the value of the stable failure rate has been determined.

This is in line with the renewal theory since the application of preventive maintenance to the components having a growing failure rate accelerates the renewal process and helps achieve the so-called state of balance faster. In this case it can be assumed that the system fails according to the law of the exponential distribution (Vujanović, 1987).

\subsection{Using the $\chi^{2}$ distribution for establishing the confidence limit in the exponential distribution}

Quite often there are no available data on any failures for some of the system components but we do know the time that component was in service. If we assume that the exponential distribution can be applied to the given component, it is possible to establish the lower confidence limit of the failure rate both for the situation where there was no failure and for the situation where there was one or more failures according to (Ivanović and Stanivuković, 1983).

The lower confidence limit for the mean time between failures $\hat{\theta}$ for the confidence interval $1-\alpha$ is given by the time, (Vujanović, 1987):

$$
\hat{\theta} \geq \frac{2 t_{r}}{\chi_{\alpha}^{2}, 2 r+2}
$$

where:

$t_{r}$ - total time of operation of the system (rotary cup burner);

$r$ - number of failures of the system (rotary cup burner);

$\chi_{\alpha}^{2}, 2 r+2$ - random changeable value belonging to the $\chi^{2}$ distribution.

In this case the upper value of the failure rate $\hat{\chi}$ for the confidence interval $1-\alpha$ is calculated from the equation:

$\hat{\chi}=\frac{\chi_{\alpha}^{2}, 2 r+2}{2 t_{r}}$

For a given value of the confidence interval $1-\alpha$ and the known number of failures $r$, the value of $\chi^{2}{ }_{\alpha}, 2 r+2$ can be determined according to Table 1 (Pavlić, 1985).

\section{RELIABILITY PREDICTION FOR THE SAACKE SKV 60 ROTARY CUP BURNER IN THE MARINE STEAM BOILER TPK/VIC 8.5/7}

The task of the fuel oil system devices is to prepare and ensure the combustion of fuel oil in the most efficient way and in line with the requirements of the plant. Combustion is a complex process occurring in multiple stages through which oil particles pass before they burn completely.

When using liquid fuel oil the combustion process involves several stages: mixing with air, heating, evaporating, thermal 
Table 1.

Probability values for the $\chi^{2}$ distribution.

\begin{tabular}{|c|c|c|c|c|c|c|c|c|c|c|}
\hline$v$ & $\chi^{2} 0.50$ & $\chi^{2} 0.30$ & $\chi^{2} 0.25$ & $\chi^{2} 0.20$ & $\chi^{2} 0.10$ & $\chi^{2} 0.05$ & $\chi^{2} 0.025$ & $\chi^{2} 0.01$ & $\chi^{2} 0.005$ & $v$ \\
\hline 1 & 0.455 & 1.074 & 1.323 & 1.642 & 2.706 & 3.841 & 5.024 & 6.635 & 7.879 & 1 \\
\hline 2 & 1.386 & 2.408 & 2.773 & 3.219 & 4.605 & 5.991 & 7.378 & 9.210 & 10.597 & 2 \\
\hline 3 & 2.366 & 3.665 & 4.108 & 4.642 & 6.251 & 7.815 & 9.348 & 11.345 & 12.838 & 3 \\
\hline 4 & 3.357 & 4.878 & 5.385 & 5.989 & 7.779 & 9.488 & 11.143 & 13.277 & 14.860 & 4 \\
\hline 5 & 4.351 & 6.064 & 6.626 & 7.289 & 9.236 & 11.070 & 12.832 & 15.086 & 16.750 & 5 \\
\hline 6 & 5.348 & 7.231 & 7.841 & 8.558 & 10.645 & 12.592 & 14.449 & 16.812 & 18.548 & 6 \\
\hline 7 & 6.346 & 8.383 & 9.037 & 9.803 & 12.017 & 14.067 & 16.013 & 18.475 & 20.278 & 7 \\
\hline 8 & 7.344 & 9.524 & 10.219 & 11.030 & 13.362 & 15.507 & 17.535 & 20.090 & 21.955 & 8 \\
\hline 9 & 8.343 & 10.656 & 11.389 & 12.242 & 14.684 & 16.919 & 19.023 & 21.666 & 23.589 & 9 \\
\hline 10 & 9.342 & 11.781 & 12.549 & 13.442 & 15.987 & 18.307 & 20.483 & 23.209 & 25.188 & 10 \\
\hline 11 & 10.341 & 12.899 & 13.701 & 14.631 & 17.275 & 19.675 & 21.920 & 24.725 & 26.757 & 11 \\
\hline 12 & 11.340 & 14.011 & 14.845 & 15.812 & 18.549 & 21.026 & 23.337 & 26.217 & 28.300 & 12 \\
\hline 13 & 12.340 & 15.119 & 15.984 & 16.985 & 19.812 & 22.362 & 24.736 & 27.688 & 29.819 & 13 \\
\hline 14 & 13.339 & 16.222 & 17.117 & 18.151 & 21.064 & 23.685 & 26.119 & 29.141 & 31.319 & 14 \\
\hline 15 & 14.339 & 17.322 & 18.245 & 19.311 & 22.307 & 24.996 & 27.488 & 30.578 & 32.801 & 15 \\
\hline 16 & 15.338 & 18.418 & 19.369 & 20.465 & 23.542 & 26.296 & 28.845 & 32.000 & 34.267 & 16 \\
\hline 17 & 16.338 & 19.511 & 20.489 & 21.615 & 24.769 & 27.587 & 30.191 & 33.409 & 35.718 & 17 \\
\hline 18 & 17.338 & 20.601 & 21.605 & 22.760 & 25.989 & 28.869 & 31.526 & 34.805 & 37.156 & 18 \\
\hline 19 & 18.338 & 21.689 & 22.718 & 22.900 & 27.204 & 30.144 & 32.852 & 36.191 & 38.582 & 19 \\
\hline 20 & 19.337 & 22.775 & 23.828 & 25.038 & 28.412 & 31.410 & 34.170 & 37.566 & 39.997 & 20 \\
\hline
\end{tabular}

atomization, creation of combustible mixture, ignition and combustion. Each stage considerably affects the combustion process, and if one of the stages is not met, the fuel oil will burn incompletely (Levit, 2000).

One of the essential prerequisite for the complete combustion is a good atomization of fuel oil (Prelec, 1990), the quality of atomisation depending on:

- way of atomization;

- design features of the atomization nozzle;

- viscosity of fuel oil;

- $\quad$ surface tension of fuel oil.

Atomization is converting the liquid fuel oil into fine spray in order to facilitate the most efficient oil-air mixing in a given period of time under actual combustion conditions within a furnace. The rotary cup burner type SAACKE - SKV 60 providing the rotational fuel oil atomization is used for observing the fuel combustion, see Figure 1, according to (Instruction book, 2003).

The operational principle involves the entrance of

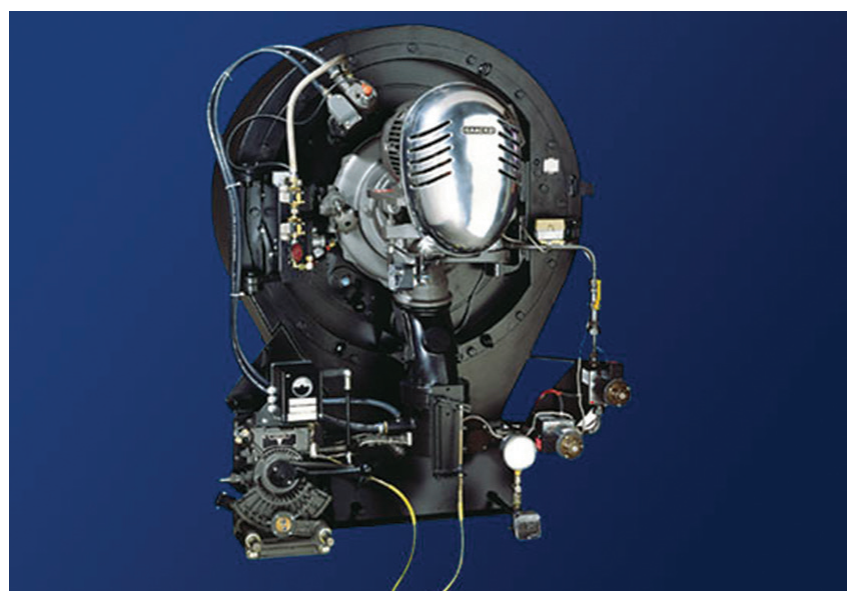

Figure 1. Rotary cup burner type SAACKE - SKV 60 Source: Operator's manual of the rotary cup burner SAACKE, type SKV 60.150, 2003. 


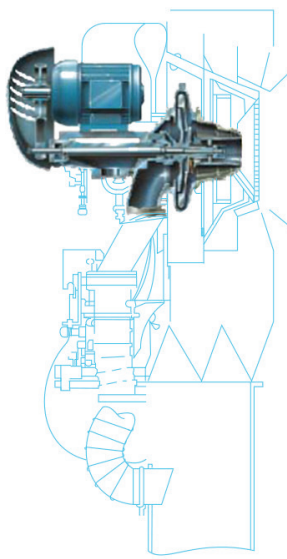

Burner swing-out assembly/ Rotary atomizing cup and primary air fan with the common drive/Gas-electric or light oil-electric ignition.

Figure 2. Rotary atomization of fuel oil and the oil compound regulator Source: Operator's manual of the rotary cup burner SAACKE, type SKV 60.1502003.
SAACKE Compound
regulation system/Actuatin

of rotary oil valve, gas control damper, primary and secondary air dumpers.
antrol damper, primary - pressurized fuel oil into the channels of whirling boxes where it gains rotary motion. After that, it passes through the coneshaped nozzle and is atomized in the burner with the aid of primary air, see Figure 2 (Instruction book, 2003).

The motion of the rotary cup burner is ensured by electromotor drive that is connected to the cone-shaped cup by means of the belt. Oil enters the cone cup through the central channel. Due to the rotation of the cone cup, the fuel oil gains rotary and axial motion and is directed to the open part of the cup towards the burner.

An independent fan drives the combustion primary air around the rim of the cup. The combustion air intersects the film of fuel oil, increasing its atomization and allowing for the initial burning. The amount of the primary air makes $15 \%$ of the air needed for combustion. The remaining air is brought through separate channels across the secondary air damper, according to (Solberg et al, 2008b).

Levers connect the dampers to the fuel oil flow control component - the oil compound regulator, as shown in Figure 2. The fuel oil pressure in the rotary cup burner is ensured by the supply pump and ranges from 2.5 - 5.0 bar. Efficient oil atomization is achieved at the kinematic viscosity of $13 \mathrm{~mm}^{2}$ and fuel oil temperature of about $130^{\circ} \mathrm{C}$.

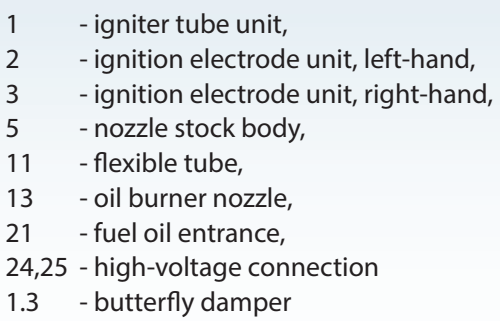

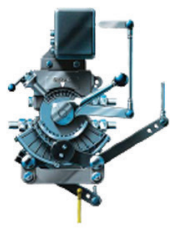

$$
13,14
$$
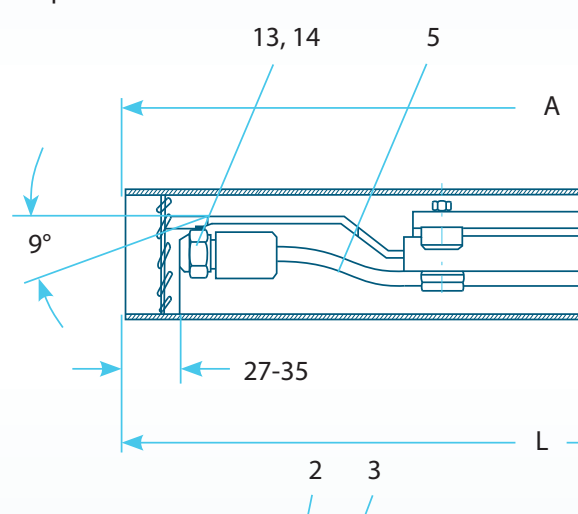

A
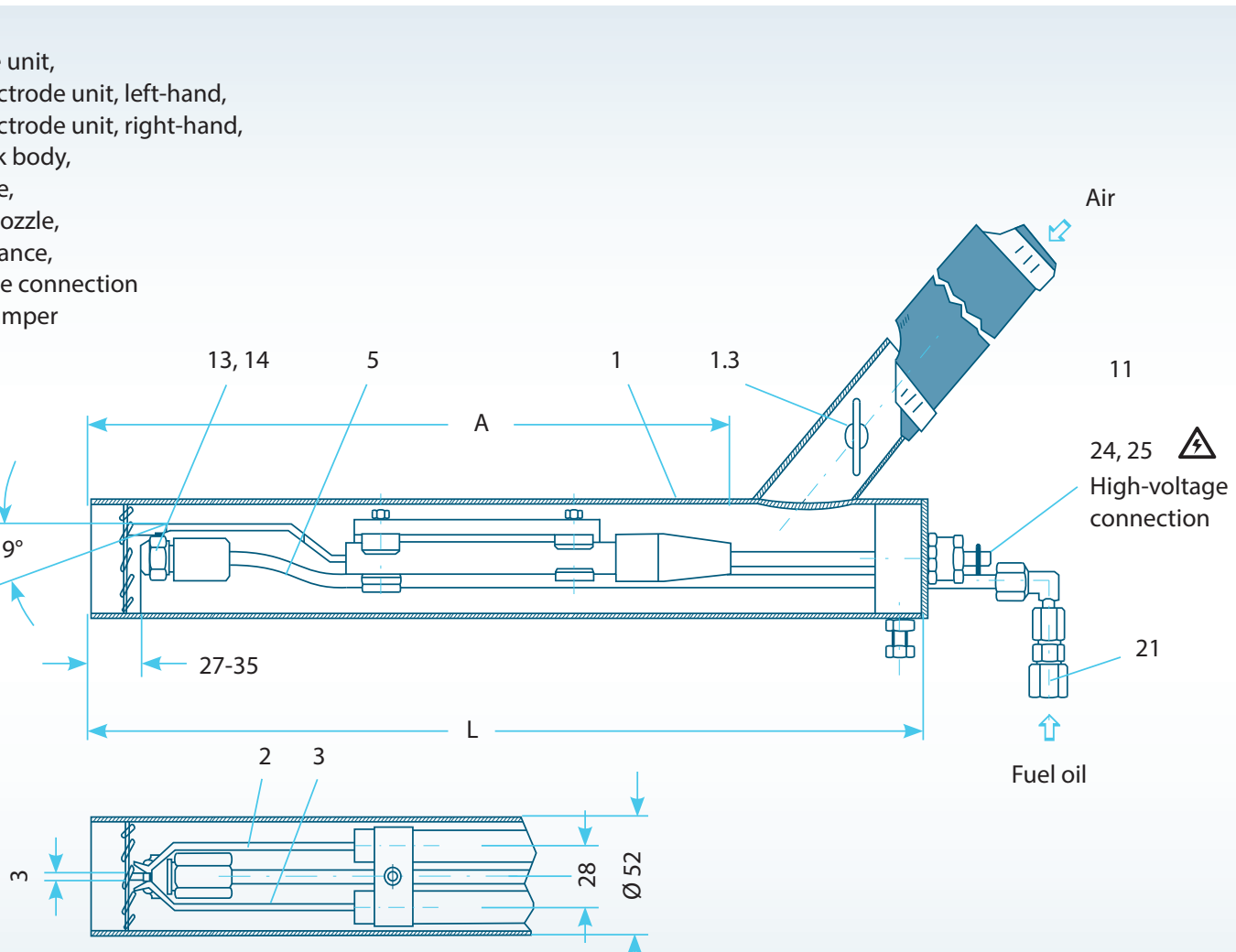

Fuel oil

Figure 3.

Light oil igniter. 
The rotary cup burner features a wide range of efficiency and automated operations of the functions (Solberg et al., 2008a), such as:

- ventilation of the furnace;

- $\quad$ ignition of the mixture;

- load regulation.

Initial oil ignition is performed by the light oil igniter. This light oil igniter is used for automatic ignition of the SKV rotary cup burner. It atomizes the light oil at 14 bar. The light oil is atomized through the nozzle and is ignited by a high-voltage spark that is created between two electrodes ( $10000 \mathrm{~V})$. The air that is needed for combustion is brought from the central register and the necessary amount of air is achieved by the integrated butterfly damper, see Figure 3 (Instruction book, 2003).

On the basis of the data available from the engine log and the technical references supplied by the manufacturer, it is necessary to predict the operational reliability of the rotary cup burner.

In addition, it should be ascertained whether the predicted operational reliability meets the previously set requirements and then, on the basis of the findings gathered, we should be able to conclude whether it is necessary to take adequate measures for increasing the reliability.

The basic requirement that is set for the rotary cup burner's reliability refers to the number of operation hours during the ship's time in port. It is required that the rotary cup burner operates for 600 hours before overhaul with reliability of no less than 0.75 . Twenty rotary cup burners are used for examination of reliability.

\subsection{Block diagram of the rotary cup burner type SAACKE - SKV 60}

If the level of complexity of the rotary cup burner's components is determined, the components may be presented as separate blocks of the subsystem, as shown in Figure 4 (Vujanović, 1987), where:

A rotary cup atomizer SKV 60;

$B \quad$ light oil igniter;

C oil compound regulator;

D combustion air fan.

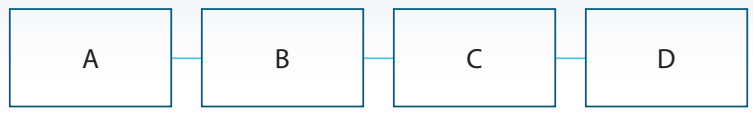

Figure 4. Block diagram of the rotary cup burner type SAACKE - SKV 60.
The rotary cup burner components are serially interdependent. Given the requirement that the rotary cup burner should be able to operate 600 hours before overhaul at the reliability value of 0.75 , the failure rate can be calculated according to (1):

$$
\lambda_{g}=-\frac{\ln R_{g}}{t}=-\frac{\ln 0.75}{600}=47.95 \cdot 10^{-5} \text { failures } / \text { hour }
$$

where:

$R_{g} \quad$ reliability of the rotary cup burner;

$\lambda_{g} \quad$ failure rate of the rotary cup burner;

$t$ required time of reliable operation of the rotary cup burner.

The mean time between failure, according to (3) is:

$$
M g=\frac{1}{\lambda_{g}}=\frac{1}{47.95 \cdot 10^{-5}}=2085.5 \text { hours }
$$

\subsection{Determining the failure rate for the basic subsystems}

\subsubsection{Rotary cup atomizer SKV 60}

The rotary cup atomizer SKV 60 consists of 15 basic parts shown in Figure 5 (Vujanović, 1987). Each basic part may be composed of a number of elements, where:
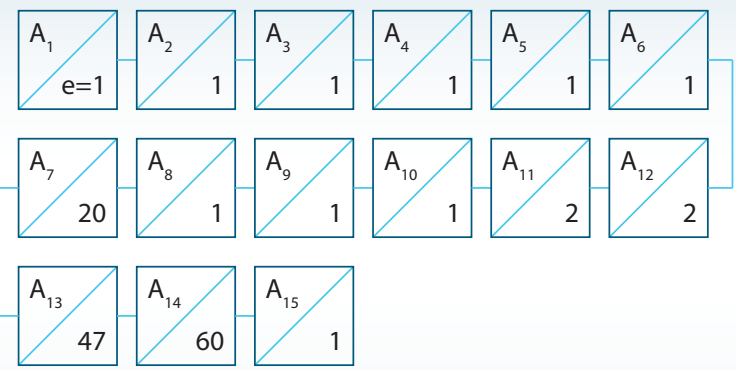

Figure 5. Block diagram of the rotary cup atomizer SKV 60.

e number of elements;

$A_{1} \quad$ system for directing the primary air;

$A_{2}$ rotary cup;

$A_{3}$ shaft;

$A_{4} \quad$ primary air fan;

$A_{5}$ electromotor;

$A_{6}$ poly- $\mathrm{V}$ belt;

$A_{7}$ strap-wheels;

$A_{8}$ ball bearings;

$A_{9} \quad$ primary air regulation damper; 
$A_{10} \quad$ safety cover;

$A_{11}$ seal;

$A_{12}$ studs;

$A_{13}$ nuts;

$A_{14}$ shims;

$A_{15}$ fuel line.

The rotary cup atomizer SKV 60 subsystem experienced failures of the basic part $A_{2}$ after 100 hours of operation, the part $A_{6}$ failed after 530 hours, whereas the part $A_{11}$ failed after 586 hours of operation.

The total number of the rotary cup atomizer SKV 60 elements is 141, which makes 2820 elements in 20 burners.

The failure rate function $\lambda_{g}$ is equal to the ratio of failure occurrences in the time interval $\Delta t$ to the number of functioning elements in the system at the end of the interval.

The failure rate functions $\lambda_{g}$ for parts $A_{2^{\prime}} A_{6^{\prime}} A_{11}$ are:

$\lambda_{A_{2}}=\frac{1}{2819 \cdot 100}=3.547 \cdot 10^{-6}$ failures $/$ hour

$\lambda_{A_{6}}=\frac{1}{2819 \cdot 530}=0.669 \cdot 10^{-6}$ failures $/$ hour

$$
\lambda_{A_{11}}=\frac{1}{2819 \cdot 586}=0.605 \cdot 10^{-6} \text { failures } / \text { hour }
$$

The failure rate of the rotary cup atomizer SKV 60 subsystem, according to (2) amounts to:

$$
{ }^{\lambda} A={ }^{\lambda} A_{2}+{ }^{\lambda} A_{6}+{ }^{\lambda} A_{11}=4.821 \cdot 10^{-6} \text { failures } / \text { hour }
$$

\subsubsection{Light oil igniter}

The light oil igniter is a subsystem comprising 14 basic parts which are shown in Figure 6 (Vujanović, 1987). Each basic part may consist of a number of elements, where:

e number of elements;

$B_{1}$ electrodes;

$B_{2}$ nozzle;

$B_{3} \quad$ filter;

$B_{4} \quad$ butterfly air damper;

$B_{5}$ high-voltage cables;

$B_{6}$ high-voltage point;

$B_{7}$ electromagnetic valves;

$B_{8} \quad$ fuel oil pump;

$B_{9}$ nuts;

$B_{10}$ shims;

$B_{11} \quad$ fuel oil line;

$B_{12}$ flexible air line;

$B_{13}$ seals;

$B_{14}$ studs.
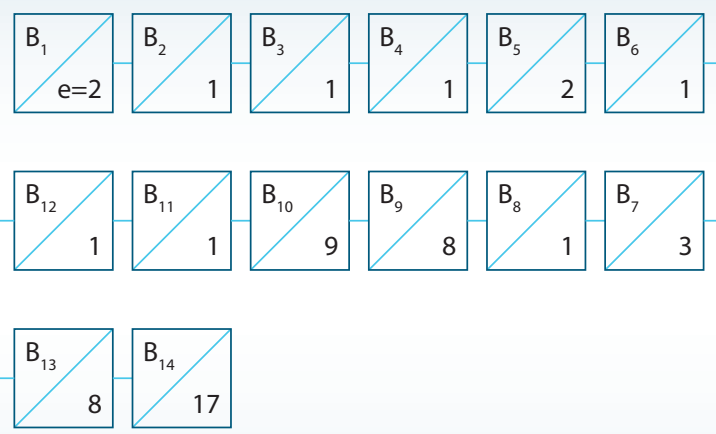

Figure 6. Block diagram of the light oil igniter.

The light oil igniter subsystem experienced failures in basic parts: $B_{2}$ after 149 hours and 450 hours of operation, $B_{3}$ after 160 hours, 325 hours and 550 hours of operation, $B_{7}$ after 495 hours of operation, $B_{11}$ after 580 hours of operation.

There were altogether 7 failures of 4 basic parts of the light oil igniter. The total number of the light oil igniter parts is 56, i.e. this makes a total of 1120 parts for 20 burners.

The failure rate functions $\lambda_{g}$ for parts $B_{2^{\prime}} B_{3^{\prime}} B_{7^{\prime}} B_{11}$ are:

$$
\begin{aligned}
& \lambda_{B_{2}}=\frac{2}{1118 \cdot \frac{149+450}{2}}=5.962 \cdot 10^{-6} \text { failures } / \text { hour } \\
& \lambda_{B_{3}}=\frac{3}{1117 \cdot \frac{160+325+550}{3}}=7.784 \cdot 10^{-6} \text { failures } / \text { hour } \\
& \lambda_{B_{7}}=\frac{1}{1117 \cdot 495}=1.805 \cdot 10^{-6} \text { failures } / \text { hour } \\
& \lambda_{B_{11}}=\frac{1}{1119 \cdot 580}=1.54 \cdot 10^{-6} \text { failures } / \text { hour }
\end{aligned}
$$

The failure rate of the light oil igniter subsystem, according to (2), amounts to:

$$
\lambda_{B=}{ }^{\lambda} B_{2}+{ }^{\lambda} B_{3}+{ }^{\lambda} B_{7}{ }^{\lambda} B_{11}=17.091 \cdot 10 \text { failures } / \text { hour }
$$

\subsubsection{Oil compound regulator}

The oil compound regulator is a subsystem comprising 12 basic parts. Each of these parts may consist of a number of elements, as shown in Figure 7 (Vujanović, 1987), where:

e number of elements;

$C_{1}$ servomotor;

$C_{2}$ control disc;

$C_{3}$ rotary valve;

$C_{4}$ micro-switch;

$C_{5}$ levers; 

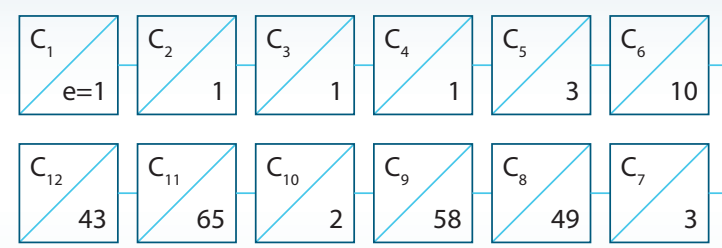

Figure 7. Block diagram of the oil compound regulator.

$\begin{array}{ll}C_{6} & \text { slide bearings; } \\ C_{7} & \text { fuel oil lines; } \\ C_{8} & \text { nuts; } \\ C_{9} & \text { shims; } \\ C_{10} & \text { shafts; } \\ C_{11} & \text { studs; } \\ C_{12} & \text { round wedges. }\end{array}$

During 600 hours of operation of the oil compound regulator two failures occurred in the basic parts: $C_{7}$ failed after 530 hours of operation due to fuel oil leaking in the return fuel oil line, while $C_{5}$ failed after 597 hours of operation due to the broken lever for regulating the primary air damper.

The overall number of the observed elements of the oil compound regulator subsystem is 237 , i.e. there are 4740 such elements in 20 oil compound regulators.

The failure rate functions $\lambda_{9}$ for parts $C_{7}$ and $C_{5}$ are:

$$
\begin{aligned}
& \lambda_{C_{5}}=\frac{1}{4739 \cdot 597}=0.353 \cdot 10^{-6} \text { failures } / \text { hour } \\
& \lambda_{C_{7}}=\frac{1}{4739 \cdot 530}=0.398 \cdot 10^{-6} \text { failures } / \text { hour }
\end{aligned}
$$

The failure rate of the oil compound regulator subsystem, according to (2), is:

$$
{ }^{\lambda} C={ }^{\lambda} C_{5}+{ }^{\lambda} C_{7}=0.751 \cdot 10^{-6} \text { failures } / \text { hour }
$$

\subsubsection{Combustion air fan}

The combustion air fan is a subsystem comprising 6 basic

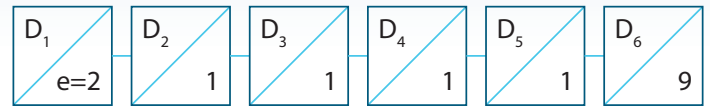

Figure 8. Block diagram of the combustion air fan. parts, and each part may consist of a number of elements, as shown in Figure 8 (Vujanović, 1987), where:

e number of elements;

$D_{1} \quad$ ball bearings;

$D_{2}$ impeller;

$D_{3}$ shaft;

$D_{4}$ safety cover;

$D_{5}$ electromotor;

$D_{6}$ studs.

During the observation period there was only one failure that occurred after 593 hours of operation due to the seizure of one of the electromotor ball bearings. The total number of the observed elements in the combustion air fan is 15 , which makes a total of 300 elements in 20 combustion air fans.

The failure rate of the combustion air fan subsystem is:

$$
\lambda_{D}=\frac{1}{299 \cdot 593}=5.639 \cdot 10^{-6} \text { failures } / \text { hour }
$$

\subsection{Determining the confidence limit of the rotary} cup burner's operation in the case of the exponential distribution of failures

A total of 20 burners were observed over a period of 600 hours of operation. According to the engine log data the overall operation time of the rotary cup burners amounted to 8,900 hours. During that time there were 8967 functional elements.

The lower confidence limit for the confidence interval $(1-\alpha)=0.75$ is obtained according to (4).

$$
\hat{\theta} \geq \frac{2 \cdot t_{r}}{x_{0.25 ; 2}^{2}}=\frac{2 \cdot 8900}{2.773}=6419.04 \text { hours }
$$

The value $x_{0.25 ; 2}^{2}$ is obtained from Table 1 .

The upper failure rate value for the functional elements during the confidence interval $(1-\alpha)=0.75$ according to (5), is:

$$
\hat{\lambda}=\frac{1}{\hat{\theta}}=\frac{1}{6419.04}=15.5786 \cdot 10^{-5} \text { failures } / \text { hour }
$$

If the obtained value is divided by the number of functional elements, the upper value of the failure rates for each separate element in the given confidence interval:

$$
\hat{\lambda}_{E L}=\frac{15.5786 \cdot 10^{-5}}{8967}=17.37325 \cdot 10^{-5} \text { failures } / \text { hour }
$$

\subsection{Determining the operational reliability of the rotary cup burner SKV 60}

Calculation of failure rates for individual parts of the rotary cup burner SKV 60 can be performed using the obtained upper failure rate in the given confidence interval:

For the rotary cup atomizer SKV 60: 


$$
\begin{aligned}
\lambda_{A_{u k}} & =\lambda_{A}+n_{A}+\hat{\lambda}=4.821 \cdot 10^{-6}+2817 \cdot 17.37325 \cdot 10^{-9}= \\
& =53.7614 \cdot 10^{-6} \text { failures } / \text { hour }
\end{aligned}
$$

For the light oil igniter:

$$
\begin{aligned}
\lambda_{B_{u k}} & =\lambda_{B}+n_{B}+\hat{\lambda}=17.091 \cdot 10^{-6}+1113 \cdot 17.37325 \cdot 10^{-9}= \\
& =36.4274 \cdot 10^{-6} \text { failures } / \text { hour }
\end{aligned}
$$

For the oil compound regulator:

$$
\begin{aligned}
\lambda_{C_{u k}} & =\lambda_{C}+n_{C}+\hat{\lambda}=0.751 \cdot 10^{-6}+4738 \cdot 17.37325 \cdot 10^{-9}= \\
& =83.0655 \cdot 10^{-6} \text { failures } / \text { hour }
\end{aligned}
$$

For the combustion air fan:

$$
\begin{aligned}
\lambda_{D_{u k}} & =\lambda_{D}+n_{D}+\hat{\lambda}=5.639 \cdot 10^{-6}+299 \cdot 17.37325 \cdot 10^{-9}= \\
& =10.8336 \cdot 10^{-6} \text { failures } / \text { hour }
\end{aligned}
$$

The prediction of the failure rate values for the rotary cup burner SKV 60 components amounts to:

$$
\begin{aligned}
\lambda_{g} & =(53.7614+36.4274+83.0655 .10 .8336) \cdot 10^{-6}= \\
& =184.0879 \cdot 10^{-6}
\end{aligned}
$$

The mean time between failures of the rotary cup burner SKV 60, according to (3), is:

$$
M_{g}=\frac{1}{\lambda_{g}}=5432.187 \text { hours }
$$
SKV 60 is:

The overall operational reliability of the rotary cup burner

$$
R_{g}=e^{-\lambda g^{t}}=e^{-0.11045274}=0.8954
$$

\section{CONCLUSION}

The obtained operational reliability of the rotary cup burner type SAACKE - SKV 60 is higher than the reliability that is required, amounting to 0.75 . The analysis of the failure rates of the rotary cup burner subsystems and the elements within the subsystems results in the conclusion that the light oil igniter is the most sensitive component of the SAACKE SKV 60 burner. include:

The most common reasons for failure in this subsystem

- fuel oil filter clogging due to impurities in fuel oil;

- contaminated electrodes;

- due to vibrations during the operation of the system, a change in the distance between the electrodes may occur, so that the electric arc intended for oil ignition cannot be produced between them.

This implies that it is necessary to undertake further research on new technological and design solutions in manufacturing the burners.

\section{REFERENCES}

Instruction book, (2003), Operator's manual of the rotary cup burner SAACKE, type SKV 60.150, Bremen: SAACKE.

Ivanović, G. and Stanivuković, D., (1983), Pouzdanost tehničkih sistema, Belgrade: University of Belgrade, Faculty of Mechanical Engineering.

Levit, G. T., (2000), Optimizing the control of combustion in steam boilers equipped with pulverizing fans, Thermal Engineering, 47(8), pp. 715-718.

Nikolić, I., (2003/2004), Pouzdanost tehničkih sistema i ljudskog faktora, Teorija, primeri, softver, Lecturer notes, Belgrade: University of Belgrade, Faculty of Organizational Sciences.

Pavlić, I., (1985), Statistička teorija i primjena, Zagreb: Tehnička knjiga.

Prelec, Z., (1990), Brodski generatori pare, Zagreb: Školska knjiga.

Solberg, B., Andersen, P., Maciejowski, J. M. and Stoustrup, J., (2010), Optimal switching control of burner setting for a compact marine boiler design, Control Engineering Practice, 18(6), pp. 665 - 675., http://dx.doi.org/10.1016/j.conengprac.2010.03.009

Solberg, B., Andersen, P. and Stoustrup, J., (2008), Modelling and Control of a Turbocharged Burner Unit, Proc. 21st International Conference on Efficiency, Cost, Optimization, Simulation and Environmental Impact of Energy Systems (ECOS 2008), Kraków, Poland, June 24-27, pp. 886 - 903, available at: http://vbn.aau.dk/ files/14600285/ecos2008_paper069.pdf, [accessed 12 October 2012.].

Vujanović, N., (1987), Teorija pouzdanosti tehničkih sistema, Belgrade: Vojno izdavački novinski centar / Military Publishing and Press Center. 